\title{
Evaluation of a clinical communication programme for perioperative and surgical care practitioners
}

\author{
Debra Nestel, ${ }^{1}$ Roger Kneebone, ${ }^{2}$ Alison Barnet, ${ }^{2}$ Tanya Tierney, ${ }^{2}$ Ara Darzi ${ }^{2}$
}

- A supplementary appendix is published online only. To view these files please visit the journal online (http://qshc.bmj. com).

${ }^{1}$ Gippsland Medical School, Monash University, Churchill, Victoria, Australia ${ }^{2}$ Department of Biosurgery \& Surgical Technology, Imperial College London, London, UK

\section{Correspondence to}

Professor Debra Nestel, Gippsland Medical School, Faculty of Medicine, Nursing \& Health Sciences, Monash University, Northways Road, Churchill 3842, Victoria, Australia; debra.nestel@med. monash.edu.au

Accepted 25 February 2009 Published Online First 21 April 2010

\section{ABSTRACT}

Introduction Communication is integral to clinical work. This paper describes a communication programme (CP) designed for two new professional roles. Training in communication is often focused on interactions with patients. Equally important is supporting clinicians to communicate with each other. The authors devised a CP for perioperative specialist and surgical care practitioners. Methods The CP spanned the broader training programme. The evaluation combined trainees' selfratings, value of educational methods, summative assessments, written reflections and focus groups. Results The CP was offered over three consecutive years (29 trainees) and showed a progressive increase in trainees' satisfaction. Educational methods were valued. Trainees appreciated the close alignment of CP content and work. Some trainees initially placed little value on learning communication, since they were already experienced clinicians. The CP was perceived to be competing with topics of greater importance. As trainees progressed, all recognised the benefits and valued the opportunity for protected time to focus on commonly used skills. Trainees reported increased awareness and ability in patient-centred and other professional communications. Most trainees were successful in summative assessments. Faculty observations noted benefits accruing from increased alignment of content with clinical practice.

Discussion Trainees responded positively to an experiential CP underpinned by education and communication theory. The opportunity for distributed learning enabled trainees to consolidate learning. The balance of teaching patient- and colleague-focused communication was successful. The framework of this $\mathrm{CP}$ is applicable to trainees in medical and other health professional roles.

\section{INTRODUCTION}

Teaching and learning about communication in health professional curricula have traditionally focused on clinician-patient interactions. ${ }^{1-4} 5$ However, this is only one component of communication essential for effective practice. Communication with colleagues is crucial for patient safety. Although well established and acknowledged by professional organisations, ${ }^{5} 6$ communication with colleagues has received less attention in training programmes.

Methods for teaching and learning about communication are varied. Early studies identified that clinician interviews with real or simulated patients (SPs) followed by expert review of the videotaped interaction are effective. ${ }^{7} 8$

This paper is based on Perioperative Specialist Practitioners (PSPs) and Surgical Care Practitioners
(SCPs), two roles where non-medically qualified healthcare practitioners take on functions traditionally associated with doctors. Although the SCP role has been evolving over many years within the UK, the PSP role was created as a direct response to the Working Time Directive, ${ }^{10}$ with its dramatic reduction in doctors' working hours. In 2002, our university teaching hospital in central London established pilot courses for both roles, funded by the UK government. Participants included nurses and those from professions allied to medicine. We use the term 'practitioner' to refer to both PSPs and SCPs. 'Trainee' describes participants attending the programmes.

Developing a new healthcare professional role (PSP) offered a 'blank sheet' to design from scratch a curriculum to meet that role's specific needs. From the outset we recognised the crucial importance of communication. The new role meant there were few preconceived ideas about expected competencies and no established curriculum within which to negotiate teaching time. Key constraints were budgetary, length of course and numbers of participants. This created an exciting and highly unusual opportunity to deliver an intensive clinical communication programme (CP) over 10 months to small groups of trainees.

\section{PERIOPERATIVE SPECIALIST PRACTITIONERS}

The PSP's role is to provide ward-based care for surgical patients in hospitals. PSPs integrate preand postoperative care, accompanying each patient from admission to discharge. ${ }^{10}$ Effective coordination of patient care aims to minimise duplication of tasks and reduce unnecessary delays. PSPs work closely with consultants acting as a focal point for communication within and beyond the surgical unit and providing continuity as junior medical staff rotate.

PSPs' responsibilities include preoperative assessment, requesting and interpreting clinical tests, discussing implications of surgery with patients and relatives, providing postoperative care and pain control, recognising and managing postoperative complications, identifying clinical deterioration, referring, coordinating the discharge process and liasing with community services. High levels of communication lie at the heart of this new role.

\section{SURGICAL CARE PRACTITIONERS}

SCPs also work within a surgical team but focus on operative procedures. SCPs may assist at surgical operations or carry out elements of procedures under supervision. They require knowledge and skills for pre- and postoperative care and an understanding of the wider aspects of surgical 
practice. Most SCPs work in the operating theatre. SCPs also require high levels of communication skill.

\section{PSP/SCP CURRICULUM}

The 10-month curriculum consisted of nine intensive week long modules interspersed with supervised experience in clinical placements. Key elements of the curricula are summarised in box 1. More detailed information is available. ${ }^{11-13}$ Practitioners are expected to perform at the standard of second year doctors (Foundation Year 2). ${ }^{14}$

\section{DESIGNING A COMMUNICATION PROGRAMME}

We wished to create an integrated communications 'spine' to run through the curriculum and be built on by each participant as they adopted their new role.

In developing the $\mathrm{CP}$, we considered:

- medical and healthcare professional literature on CP content and educational methods;

- broad range of professional interactions that require communication;

- relationship of communication to patient safety;

- importance of aligning content with the broader curriculum;

- trainees' existing knowledge and experience in communication;

- qualitative evaluations from an initial pilot PSP programme. The CP is underpinned by generic principles of interpersonal communication. ${ }^{15} 16$ Practitioners take responsibility for anticipating, identifying and acknowledging the communication needs of the recipient (patient or colleague). Interactions can be formal or informal, direct or indirect, verbal and/or non-verbal.

Twelve sessions provided $26 \mathrm{~h}$ of communication teaching (box 2). After an introductory meeting, sessions focused on specific elements of communicating with patients and colleagues, finishing with a review of the entire CP. Educational methods included readings, discussions, brainstorming, trigger videotapes, role-play, DVD review, SPs, hybrid simulations and written reflections (online appendix).

Sessions took place in our clinical skills centre with purpose built teaching facilities, including consultation rooms linked to adjacent observation rooms equipped with digital audio and video recording equipment. Role-play interactions were recorded on DVDs.

\section{Box 1 Outline of the overall curriculum}

Forty-eight training days (nine intensive 5-day modules at 3-4-week intervals and three additional days) over 10 months Key elements included:

- Factual knowledge (eg, anatomy, clinical physiology, preassessment, anaesthesia, surgery, postoperative complications)

- Clinical skills (eg, clinical examination, venepuncture, intravenous infusion, bladder catheterisation, arterial blood gas estimation)

- Team working skills (eg, awareness of team dynamics, professional interplay, managing hostility)

- Professional issues (eg, record-keeping, medicolegal issues, prescribing)

- Personal development (eg, learning portfolios, reflective writing, issues around role evolution)

- Communication skills (eg, history taking, consent for surgery, breaking bad news, presenting clinical information to colleagues)
Box 2 Session topics for the communication programme (numbers in parentheses represent length of study in minutes)

(1) Introduction to learning about clinical communication (60) Practitioner-patient communication

(2) Patient assessment I (90)

(3) Patient assessment II (120)

(4) Giving information to patients (120)

(5) Giving information to patients: breaking bad news (180)

(6) Communicating during procedures (180)

(7) Different languages and working with interpreters (120)

Practitioner-healthcare professional communication

(8) Feedback (120)

(9) Case presentations and handovers (180)

(10) Communicating critical information (180)

(11) Written communication (90)

(12) Review of the clinical CP (120)

Trainees were provided with a session guide made available electronically in advance enabling effective use of contact time for experiential activities. The guide contained learning objectives (table 1), activities and relevant theoretical materials with questions that drew on the trainees' experiences. All sessions began with a 'progress' report and an opportunity to raise any communication issues from clinical practice. Sessions ended with a review of the learning objectives, educational methods and plans for practising skills.

The programme was delivered by three communication tutors, each with extensive experience of working in medical and nursing education. Additional support was provided by practitioners who had previously undertaken the curriculum.

\section{ASSESSMENT}

Formative assessments took place in every session. Self-assessment was strongly encouraged. Supervised clinical experience between sessions was an essential component of the whole course. This cemented the integration of CP teaching with procedural and other key clinical skills.

Summative assessment is a mandatory component of the wider practitioner curricula. We designed a procedural skills assessment that reflected scenarios trainees were likely and expected to be able perform. These hybrid simulations ${ }^{17} 18$ included a patient (actor) 'attached' to a benchtop model (eg, urinary catheterisation, suturing) or had a procedure performed (eg, ECG) or was an actor playing the role of a patient being prepared for surgery.

Trainees were required to complete written reflections on clinical experiences which included an element of communication. ${ }^{19}$

\section{EVALUATION METHODOLOGY}

Demographic information was recorded on admission to the course.

\section{Session evaluations by trainees}

At the end of every session, trainees used a three-point scale to rate the degree to which they met learning objectives and the value of the educational methods. Free text comments were invited. During the review, trainees completed 
Table 1 Trainees' ratings of the degree to which they 'completely' met the learning objectives (numbers in parentheses represent the number of trainees at the session)

\begin{tabular}{|c|c|c|c|c|c|c|}
\hline \multirow[b]{2}{*}{ Learning objective } & \multicolumn{2}{|c|}{ Cohort 12005} & \multicolumn{2}{|c|}{ Cohort 22006} & \multicolumn{2}{|c|}{ Cohort 32007} \\
\hline & No & $\%$ & $\overline{\text { No }}$ & $\%$ & No & $\%$ \\
\hline Explain the concept of patient centred care & $8(14)$ & 57 & $7(8)$ & 88 & $8(9)$ & 89 \\
\hline Review evidence for patient centred approaches to communicating & $8(14)$ & 57 & $7(8)$ & 88 & $8(9)$ & 89 \\
\hline Reflect on how this evidence relates to their own clinical practice & $8(14)$ & 57 & $7(8)$ & 88 & $7(9)$ & 78 \\
\hline Outline models of patient centred consultations & $9(14)$ & 64 & $7(8)$ & 88 & $8(9)$ & 89 \\
\hline Consider partnership models for relationships with patients & $8(14)$ & 57 & $7(8)$ & 88 & $8(9)$ & 89 \\
\hline Identify your strengths in patient assessment & $8(13)$ & 62 & $7(8)$ & 88 & $8(9)$ & 89 \\
\hline Identify your areas for development in patient assessment & $8(13)$ & 62 & $7(8)$ & 88 & $8(9)$ & 89 \\
\hline Identify challenges when giving (and receiving) feedback to (and from) colleagues & $9(13)$ & 69 & $7(8)$ & 88 & $8(9)$ & 89 \\
\hline Discuss strategies for giving effective feedback & $9(13)$ & 69 & $7(8)$ & 88 & $8(9)$ & 89 \\
\hline Describe the importance of feedback for professional development & $9(13)$ & 69 & $7(8)$ & 88 & $9(9)$ & 100 \\
\hline Identify effective presentation skills & $11(11)$ & 100 & $7(7)$ & 100 & $7(7)$ & 100 \\
\hline Use effective skills for making case presentations to colleagues & $9(11)$ & 82 & $7(7)$ & 100 & $6(7)$ & 86 \\
\hline Describe principles of effective handover & $8(11)$ & 73 & $7(7)$ & 100 & $7(7)$ & 100 \\
\hline Identify your strengths and weaknesses in simulated handovers & $8(11)$ & 73 & $6(7)$ & 86 & $6(7)$ & 86 \\
\hline Identify your areas for development in handover skills & $7(11)$ & 64 & $6(7)$ & 86 & $6(7)$ & 86 \\
\hline Describe ways in which written communications are used in healthcare & $8(12)$ & 67 & $6(6)$ & 100 & $6(6)$ & 100 \\
\hline Identify key aspects of effective written communications & $8(12)$ & 67 & $6(6)$ & 100 & $6(6)$ & 100 \\
\hline List basic abbreviations and their meanings commonly used in medical histories & $11(12)$ & 92 & $6(6)$ & 100 & $5(6)$ & 83 \\
\hline $\begin{array}{l}\text { Describe ways in which a patient's individuality can be maintained in written } \\
\text { communications }\end{array}$ & $8(12)$ & 67 & $5(6)$ & 83 & $5(6)$ & 83 \\
\hline Describe general principles of information giving & $8(10)$ & 80 & $5(6)$ & 83 & $8(8)$ & 100 \\
\hline Outline how these principles are relevant in consultations & $8(10)$ & 80 & $5(6)$ & 83 & $8(8)$ & 100 \\
\hline Demonstrate competence in giving information to patients about a procedure & $7(10)$ & 70 & $5(6)$ & 83 & $7(8)$ & 88 \\
\hline Identify your areas for development in giving information to patients & $7(10)$ & 70 & $5(6)$ & 83 & $7(7)$ & 100 \\
\hline Describe principles of giving information over the telephone & $8(11)$ & 73 & $5(6)$ & 83 & $7(7)$ & 100 \\
\hline Describe the SBAR protocol for giving information about a critical situation & $8(11)$ & 73 & $5(6)$ & 83 & $6(7)$ & 86 \\
\hline Recognise that 'bad' news is defined by the recipient & $9(13)$ & 69 & $5(6)$ & 83 & $7(7)$ & 100 \\
\hline Describe attitudes and skills for sharing 'bad' news with patients & $10(13)$ & 77 & $6(6)$ & 100 & $7(7)$ & 100 \\
\hline Reflect on your ability to give 'bad' news & $10(13)$ & 77 & $5(6)$ & 83 & $7(7)$ & 100 \\
\hline Describe cultural groups to which people belong & $9(12)$ & 75 & $5(6)$ & 83 & $7(7)$ & 100 \\
\hline Identify how cultural issues may affect communication & $9(12)$ & 75 & $5(6)$ & 83 & $7(7)$ & 100 \\
\hline Identify a range of strategies for managing cross-cultural communication & $9(12)$ & 75 & $5(6)$ & 83 & $7(7)$ & 100 \\
\hline Describe difficulties that may arise if family members or relatives are used as interpreters & $9(12)$ & 75 & $5(6)$ & 83 & $7(7)$ & 100 \\
\hline Describe the skills required by healthcare professionals when working with interpreters & $9(12)$ & 75 & $5(6)$ & 83 & $7(7)$ & 100 \\
\hline
\end{tabular}

SBAR protocol, Situation, Background, Assessment, Recommendation protocol.

semistructured evaluation forms. All responses were anonymous and voluntary.

\section{Group interviews with trainees}

For the first two cohorts, trainees participated in group interviews led by an external moderator up to four times over the curriculum. The third cohort had one group interview after the final session. Interviews were semistructured and informed by a topic guide.

\section{Trainee assessments}

Summative assessments are reported as evidence of progress.

\section{Tutor evaluation}

The lead CP tutor (author DN) documented reflections after every session.

\section{Analysis}

Descriptive statistics are reported for quantitative data. Qualitative data were thematically analysed and agreement sought over key findings (DN, $\mathrm{AB})$.

The data for the three cohorts are presented separately.

\section{RESULTS}

Thirty-one trainees registered for the courses over 3 years (2004-2007) ( $n=14,8$ and 9 respectively). Two deferred, and three left for personal reasons. Ages ranged from 26 to 51 years (mean 35, 38 and 41 years, respectively), six trainees were male, and 25 were female. Groups were similar demographically.

Twenty-two trainees registered for PSP training, while nine undertook SCP training.

Trainees were drawn from a range of professional backgrounds-nursing and allied health professionals (eg, operating department practitioners, physiotherapists) and a physiologist. Trainees worked in a range of surgical specialities.

Table 2 Trainees' ratings of the value of the educational methods in meeting the learning objectives (numbers in parentheses reflect the number of trainees who attended the session in which the method was used)

\begin{tabular}{|c|c|c|c|c|c|c|}
\hline \multirow[b]{2}{*}{ Educational Method } & \multicolumn{2}{|c|}{ Cohort 12005} & \multicolumn{2}{|c|}{ Cohort 22006} & \multicolumn{2}{|c|}{$\begin{array}{l}\text { Cohort } 3 \\
2007\end{array}$} \\
\hline & $\overline{\text { No }}$ & $\%$ & No & $\%$ & No & $\%$ \\
\hline Session guide & $101(128)$ & 78.9 & $78(84)$ & 92.9 & $80(84)$ & 95.2 \\
\hline Discussion groups & $87(145)$ & 60.0 & $87(102)$ & 85.3 & $81(84)$ & 96.4 \\
\hline Role-play activities & 77 (107) & 72.0 & $67(74)$ & 90.5 & $59(64)$ & 92.2 \\
\hline Feedback from simulated patient & $67(76)$ & 88.2 & $49(56)$ & 87.5 & $47(48)$ & 92.9 \\
\hline Feedback from tutor & $87(98)$ & 88.8 & $57(67)$ & 85.1 & $50(52)$ & 96.2 \\
\hline Feedback from peers & $78(104)$ & 75.0 & $69(80)$ & 86.3 & $68(72)$ & 94.4 \\
\hline
\end{tabular}


Box 3 Trainees' free text comments immediately after sessions (number in parentheses reflects cohort). Responses are not categorised, since the main themes overlap

Role-play activity was beneficial... good to have feedback and to be able to see how you can develop skills and knowledge in a short time. (1)

I achieved a lot from the role-plays - in the form of practice and in giving and receiving feedback (although do not usually like role-plays!). Would like to have been more familiar with history-taking before carrying out the activity. (2)

Still feel role-play is 'alien' to me. Feel self-conscious about saying too much. Had true 'light bulb' moment when as an observer I was seen to not 'practice what I preached'... It was worth it for my new level of awareness. May/would be better if we got more feedback in those role-plays from the 'experts'-I understand you (tutor) cannot be everywhere. (2)

Felt very embarrassed, rushed and 'unreal' situation in role-plays. Did not enjoy role of PSP at all, but the feedback given to me was good. (1) Handover role-plays much better than day before as I was able to handover a 'real' patient who I actually saw. I could then concentrate on what I was saying (communication-wise!). (1)

When you (tutor) were present for review of our role-play, there was constructive criticism; however, we are not experienced in identifying the ideal. (3)

Being watched by 'pros' (tutors) who identify things that I would never consider and offering constructive advice on how to address it was incredibly useful. Noticed things/speech/actions that I wouldn't notice if I watched the video 100 times. (3)

Learnt a lot and realised there is no special way to do it (give urgent information to a consultant). Everyone was different but totally acceptable. (2)

Observing others perform was a good teaching aid. You could learn a lot from their verbal and non-verbal cues. Excellent session. (1)

Looking at our mannerisms, etc on video is useful though painful! (2)

Having actor (SP) to give explanation made you focus on your role as a professional and perform. Time was limited to explore aspects (concerns) the patients may have expressed. Hence, may have given a false impression of yourself as not being empathic. Group constructive criticism and learning from each others' performance was also useful. Feedback from actors was excellent. (3)

Box 4 Trainees' free text comments in the focus-group interviews (number in parentheses reflects cohort)

Some areas seemed too simplistic-for example, telephone communication whereas other areas new to me and very useful-for example, breaking bad news, gathering information for history taking, presenting info. Excellent resources and management of sessions throughout course. Have picked up lots of useful information. Much better with actors - not comfortable with role plays with colleagues, even though I interact so well with them (very unrealistic). This I found difficult, felt uncomfortable and as though I was 'acting' in a way I wouldn't normally. This didn't happen with the actors' scenarios. (1)

Early sessions I felt did not always recognise your previous experience in communication; however, this improved as we progressed through the modules. Teaching methods I found good and very thorough leaving us with valuable resources to refer to in our future practice. Role plays not so good among ourselves but excellent with actors/actresses. Learnt a lot about my communication skills. Always better with simulated patients. When we are left to do things among ourselves we tend to digress and it's not so valuable. All in all, some very valuable, eye-opening sessions. Have definitely improved my communicating skills in hospital. It has also been noted by patients in my hospital I have had positive feedback. (1)

Initially, I was skeptical that I could learn from 'communication' lecturers, as this is the 'bread and butter' of a nurse's role. However, I feel that module by module, I have taken on board the taught element and taken on board objectively the points raised by the course tutor/ simulated patients. I found the simulated patients very realistic, though peer group work less useful, as fellow PSPs were not critical for fear of causing offensive. I find in my clinical work I now think about my patient conversations making sure that patients have the opportunity to ask questions; my closure has also improved. (2)

I have found the communication components a valuable learning tool, I feel that it has helped me to develop since the beginning of the course; however, I do believe that the role play aspects with colleagues is not necessary and that simulated patients 'actors' should be used from the beginning to provide a sense of realism! Although I feel that videotaping the sessions can prove valuable for some PSPs, my experience has not been of that, I feel self conscious watching myself back on video, and for this reason I have not watched any of them back. Feedback received from tutors and simulated patients I have found very beneficial; it has made me reflect on my professional practice, and with this I have found it very good for developing my portfolio and my reflective practice. (2)

Thinking you know how to communicate and actually communicating are two different things, and I feel I have learnt better/improved techniques to communicate and improve how I do it, that is, guarded/closed/open questions, body language, repetition, etc. On reflection, I have gained huge insight into my new improved skills and feel I can communicate better with my patients and colleagues. Initially, I was very skeptical and thought I could communicate effectively, but wow!!!, I have learnt so much and most importantly I use it daily not only in my work place-this in turn has improved my professional approach. (2)

At the beginning when we don't have actors we were all stressed with the 'task' as well as the communication skills, and the feedback we gave each other was not useful. But once we knew each other and could make up our scenarios, it felt more real, and the professional standard of feedback was really useful, and I learnt a lot. (2) 


\section{Box 5 Summary reflections of the lead tutor}

\section{Strengths of the programme}

- Theoretical foundation underpinning the CP

- Experiential activities engaged trainees, especially discussions and work with simulated patients

- Creating a supportive environment (eg, the gradual introduction of role-play)

- Progressive approach to raising of awareness of high level communication skills

- Highly structured process in each session but flexibility in content enabling alignment of the CP with the clinical experience

- Maintaining momentum in sessions with a positive atmosphere

- Using a variety of role-play formats

- Providing a framework for learning skills to give and receive feedback

- Acknowledging reflection on previous practice

- Aligning content with other curriculum topics (eg, patient safety, medicolegal)

- Integrated communication with other skills (eg, procedural)

- Adopting a broad definition of communication topics

- Early progress fed back to trainees

- Open discussions at the beginning of each session enabling relevance and continuity

- Multiple opportunities for formative assessment

Challenges

- Initial resistance that there was anything further to learn about communicating

- Low priority of communication training compared with other knowledge and skills required for their new roles

- Highly critical of medical and other healthcare professionals while reluctant to critically appraise peers

- Role-play remained threatening for some trainees although it was largely acknowledged as a valuable method for learning

- Provision of more expert feedback-especially in early sessions as trainees learn how to observe and critique constructively

Twenty-four trainees reported some prior training in communication skills (eg, assertiveness training, interviewing skills). Almost all had used role-play in other courses. None had worked with SPs.

\section{Trainees' ratings of the learning objectives}

Response rates for each session were at least $84 \%$. Table 1 shows the results of the trainees' ratings of the degree to which they met learning objectives. Only the ratings for 'completely' met are included, since the item 'not at all' met was used just six times in three cohorts. The second (>83\%) and third $(>78 \%)$ programmes were more successful than the first $(>57 \%)$ in relation to trainees' ratings. Learning objectives were perceived to be met by most trainees in the second and third cohorts with improvements across all sessions.

\section{Trainees' ratings of the educational methods}

Table 2 shows trainees' ratings of the educational methods. As above, only the ratings for 'completely' valuable are included. The different whole numbers of responses for each method reflects how often the method was used. Feedback was consistently rated as valuable (75-96\%). All feedback was appreciated. The value of role-play increased as the CP evolved (72-92\%). Session guides and discussion groups were rated more favourably with each iteration.

\section{Trainees' comments after sessions}

Free text comments are listed in box 3. Most related to role-play and feedback. Trainees expressed a range of emotions (eg, nervous, self-conscious, embarrassed, joy) and highlighted difficulties in role-play. Comments from early sessions were more critical than those in later sessions. Feedback was seen as integral to role-play and 'expert' feedback from tutors and SPs was essential to support learning. Feedback from experts and SPs was preferred to that from peers.

\section{Trainees' comments in the review session}

Trainees identified changes in their knowledge and communication skills. They responded well to scenarios, found working with actors more realistic than role-play with peers, acknowledged the importance of feedback, especially from SPs, described the challenge of giving 'critical' feedback to peers and expressed discomfort with watching their DVDs.

\section{Focus-group interviews}

Forty-nine group interviews were conducted by two external moderators providing a rich source of data. All trainees were initially involved, but as the courses progressed the number of interviews was reduced. Interview group size was five to seven trainees. Evaluations showed a highly positive overall response (box 4). CP content was appropriate and the standard of teaching excellent.

Positive elements of the CP included the opportunity for honest feedback, unexpected personal development, acquisition of high-level observational skills as a basis for understanding clinical communication, working with actors to enhance realism and the use of a framework to 'analyse' interpersonal communication.

Negative elements included difficulties in pitching activities at the right level. Early in the CP, trainees reported that their needs were for factual information rather than communication skills and thus perceived that the $\mathrm{CP}$ was taking up their valuable course time. Trainees reported anxiety over role-play and too much emphasis on 'reflection.'

\section{Trainees' summative assessments}

In the first cohort, 11 attempted and 10 were successful in summative assessments. One trainee failed to complete the essay component. In the second cohort, seven trainees successfully completed the assessments (one deferment), and in the 
third cohort, eight trainees successfully completed summative assessments.

\section{Faculty reflections}

The lead tutor $(\mathrm{DN})$ recorded reflections which are summarised as strengths and challenges of the $\mathrm{CP}$ (box 5). Cohorts were observed to be similar at the start of the CP (eg, resistance to role-play, high expectations of their own communication skills). Faculty were responsive to feedback, improving educational methods to provide an increasingly supportive learning environment, acknowledged difficulties (eg, role-play, learning priorities), changed the distribution of sessions, streamlined content, aligned with clinical practice, increased simulated patient involvement and highlighted links with the broader curriculum. Using hybrid simulations to teach communication was highly valued.

\section{DISCUSSION}

Overall, this evaluation has demonstrated feasibility and perceived value of a structured CP for two emerging clinical roles. The range of topics and educational methods enabled trainees to discuss, observe, rehearse and reflect on patientcentred and colleague-focused communication. The opportunity to develop a CP with a balanced communication focus proved valuable. Providing contextualised learning experiences in the form of hybrid simulations and scenarios drawn from the practice of trainees was powerful. The small cohorts facilitated the development of close relationships while the regular meetings over 10 months enabled revisiting of basic principles.

\section{Educational theory}

The CP design drew on several education theories in selecting content and methods. Principles of adult learning ${ }^{20}$ underpinned the effective educational climate. Reflective practice influenced the structure of sessions ${ }^{21}$. Social learning theory in which the importance of observing and modelling behaviours, attitudes and emotional reactions is critical for learning was in evidence, especially in role-play and hybrid simulations to learn procedural skills. The CP also drew on principles of contextualised learning 2223 with simulated scenarios constructed from trainees' current experiences.

\section{Role-play}

Although already experienced clinicians, the trainees reported relatively little prior patient-centred communication training. Many had graduated before formal communication training was introduced to undergraduate nursing education. However, trainees had very high expectations of their performance which seemed to add to their anxieties. They felt exposed to professional (and peer) scrutiny. Emotions play an important role in learning, ${ }^{24}$ and we did not always manage this process successfully. By acknowledging these difficulties and monitoring trainees' progress throughout the $\mathrm{CP}$, role-play became more comfortable and valued for learning. ${ }^{25}$

\section{Feedback}

Although valued, feedback was not always comfortable. The results suggest that it provided affirmation of trainee's competence, gave clear guidance for developing effective skills, was motivating and gave insight to personal development. Trainees appreciated expert feedback compared with peers. A significant challenge was to ensure that the level of feedback was appropriate to trainees' needs. We wanted to support trainees in developing their ability to give feedback effectively, so it was important for us to know when to withdraw to enable trainees' to have the opportunity to develop these skills for themselves. This challenge reflects the concept of 'scaffolding.'26

\section{Evaluation strategy}

Immediate 'end of session' evaluation was seen by trainees in the context of that session and enabled us to be responsive to trainees' needs. However, evaluation through focus-group interviews and review sessions were important in identifying consolidation of learning.

\section{Areas for development}

Areas for development of the CP include site visits to support trainees in their hospitals, more team communication exercises, further integration with other professional behaviours (eg, staff appraisal skills, conflict resolution, dealing with difficult colleagues) and focused teaching on what to do when things go wrong. Additionally, workplace based assessments such as multisource or $360^{\circ}$ feedback would be valuable.

\section{Limitations}

The population size was small, and since trainees were largely self-selected for entering a new role, they may be different to other clinicians. Many of our evaluation measures deal with perceptions of learning rather than what trainees actually do in practice. This represents Kirkpatrick's lower levels (1 and 2) for evidence of impact in training programmes. ${ }^{27}$ We do not have direct evidence of changes in clinical practice (levels 3 and 4). Some trainees reported that they and others noted improved performance. Future studies could directly monitor postcourse performance. We had no baseline information to track progress since the CP was devised as an educational programme rather than a research project.

Multiple factors influence the development of communication skills, and we cannot assume that improvements in performance reported by trainees were only attributed to the CP.

\section{CONCLUSION}

In this project we had the opportunity to design and provide a prolonged, sustained and incremental CP which ran within and alongside other elements of the curriculum. Detailed evaluation from multiple perspectives allowed us to develop our curriculum design incrementally. The innovative nature of the programme allowed considerable latitude in design, together with a high level of responsiveness to the needs of each group. ${ }^{13}$ Results show a high level of satisfaction and perceived value from an integrated CP, which gives equal weight to patientcentred and colleague-focused communication.

Acknowledgements Simulated patients from The Harry Partnership NHS Modernisation Agency for funding the pilot.

\section{Competing interests None.}

Provenance and peer review Not commissioned; externally peer reviewed.

\section{REFERENCES}

1. Hargie ODW, Morrow NC. A survey of interpersonal skills teaching in pharmacy schools in the United Kingdom and Ireland. Am J Pharm Educ 1986;50:172-5.

2. Beardsley RS. Communication skills development in colleges of pharmacy. Am J Pharmaceut Educ 2001;65:307-14.

3. Chant S, Jenkinson T, Randle J, et al. Communication skills: some problems in nursing education. J Clin Nurs 2002;11:12-21.

4. Hargie 0, Dickson D, Boohan M, et al. A survey of communication skills training in UK Schools of Medicine: present practices and prospective proposals. Med Educ 1998;32:25-34. 
5. British Medical Association. Communication skills education for doctors: an update. London: BMA, 2004. http://www.bma.org.uk (accessed Jan 2010).

6. General Medical Council Tomorrow's Doctors. Recommendations for undergraduate medical education. http://www.gmc-uk.org/education/undergraduate/ tomorrows_doctors_2009.asp (accessed Jan 2010).

7. Maguire $\mathbf{P}$, Roe P, Goldberg D, et al. The value of feedback in teaching interviewing skills to medical students. Psychol Med 1978;8:695-704.

8. Maguire $\mathbf{P}$, Fairbairn S, Fletcher C. Consultation skills of young doctors: I-Benefits of feedback training in interviewing as students persist. BMJ (Clin Res Ed) 1986;292:1573-6.

9. Phillips H, Cripps J. EWTD developments. Bulletin of the Royal College of Surgeons of England 2004:6:190-2.

10. National Practitioner Programme. Curriculum framework for Perioperative Specialist Practitioners RCSEng, December 2007. London UK: Department of Health.

11. Curriculum framework for the surgical care practitioner. Gateway ref:5927. UK: Department of Health/National Health Service, April 2006

12. Kneebone R, Nestel D, Chrzanowska J, et al. The perioperative specialist practitioner-mapping a new surgical role. Qual Saf Health Care 2006; 15:354-8

13. Kneebone RL, Nestel D, Chrzanowska J, et al. Innovative training for new surgical roles-the place of evaluation. Med Educ 2006;40:987-94.

14. Foundation programme. http://www.foundationprogramme.nhs.uk/pages/foundationdoctors (accessed Jan 2010).
15. DeVito JA. The interpersonal communication book. 9th edn. USA: Addison Wesley Longman, 2001

16. Guirdham M. Interpersonal skills at work. 2nd edn. Great Britain: Prentice Hall, 1996.

17. Kneebone RL, Nestel D. Wetzel CM, et al. The human face of simulation. Acad Med 2006;81:919-24

18. Kneebone R, Nestel D, Yadollahi F, et al. Assessing procedural skills in context: an Integrated Procedural Performance Instrument (IPPI). Med Educ 2006:40:1105-14.

19. Kidd J, Nestel D. Facilitating reflection in an undergraduate medical programme. Med Teach 2004:26:481-3.

20. Knowles M. The adult learner: a neglected species. Houston, Texas: Gulf Publishing, 1990.

21. Schon D. The reflective practitioner. New York: Basic Books, 1983.

22. Lave J, Wenger E. Situated learning. Legitimate peripheral participation. Cambridge, UK: Cambridge University Press, 1991.

23. Wenger E. Communities of practice. Learning, meaning, and identity. Cambridge, UK: Cambridge University Press, 1998.

24. Tharp R, Gallimore R. Rousing minds to life. Cambridge, UK: Cambridge University Press, 1988

25. Nestel D, Tierney T. Engaging students in role-play activities: developing evidencebased guidelines. BMC Med Educ 2007;7:3. doi:10.1186/1472-6920-7-3.

26. Bruner JS. Toward a theory of instruction. Cambridge, Mass: Harvard University Press, 1967.

27. Kirkpatrick DL. Evaluating training programmes: the four levels. San Francisco: Bernett-Koehler, 1994. 